\title{
Endoscope-assisted transcranial surgery for anterior skull base meningiomas
}

\author{
Waleed A. Azab, Mohamed A. Elmaghraby, Salem N. Zaidan, Kamal H. Mostafa \\ Neurosurgery Department, Ibn Sina Hospital, Kuwait City, Safat 13115, Kuwait.
}

Correspondence to: Dr. Waleed A. Azab, Neurosurgery Department, Ibn Sina Hospital, P.O Box: 25427, Kuwait City, Safat 13115, Kuwait. E-mail: waleedazab@hotmail.com

How to cite this article: Azab WA, Elmaghraby MA, Zaidan SN, Mostafa KH. Endoscope-assisted transcranial surgery for
anterior skull base meningiomas. Mini-invasive Surg 2020:4:88. http://dx.doi.org/10.20517/2574-1225.2020.75

Received: 20 Jul 2020 First Decision: 26 Aug 2020 Revised: 4 Sep 2020 Accepted: 10 Oct 2020 Published: 10 Dec 2020

Academic Editor: Oreste de Divitiis Copy Editor: Cai-Hong Wang Production Editor: Jing Yu

\begin{abstract}
Anterior skull base meningiomas are benign, dural-based tumors that originate from the tuberculum sellae, planum sphenoidale or olfactory groove. A multitude of traditional transcranial approaches have been effectively used for resection of these tumors. However, in the era of minimally invasive neurosurgery, the endoscopic endonasal and the endoscope-assisted or endoscope-controlled supraorbital keyhole eyebrow approaches stand out as the two main options utilized to resect these tumors. The supraorbital keyhole approach minimizes brain retraction, tissue dissection and length of the skin incision. Consequently, this approach is associated with a lower complication profile and much better cosmetic results in comparison to classic approaches. With endoscopic assistance or control, the approach provides an excellent view of anterior skull base meningiomas and enables optic nerve decompression when angled scopes are used. In our opinion, endoscopes will ultimately replace the surgical microscopes as the viewing tools in this type of surgery. A limited number of studies have directly compared the endoscopic endonasal approach versus the supraorbital keyhole one for resection of anterior cranial base meningiomas. In these studies, scores and algorithms have been suggested to help select the suitable approach. The practical value of these algorithms still needs to be validated by further research. Although the endoscope-assisted or -controlled supraorbital keyhole approach offers a minimally invasive and highly effective approach for excision of anterior cranial base meningiomas, the ideal approach should be tailored to the individual patient according to the tumor size, lateral extension, optic canal involvement, extent of vascular encasement and surgeon's experience.
\end{abstract}

Keywords: Endoscope, endoscope-assisted, keyhole, meningioma, olfactory groove, planum sphenoidal, skull base, tuberculum sellae

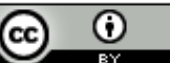

(C) The Author(s) 2020. Open Access This article is licensed under a Creative Commons Attribution 4.0 International License (https://creativecommons.org/licenses/by/4.0/), which permits unrestricted use sharing, adaptation, distribution and reproduction in any medium or format, for any purpose, even commercially, as long as you give appropriate credit to the original author(s) and the source, provide a link to the Creative Commons license, and indicate if changes were made. 


\section{INTRODUCTION}

Anterior skull base meningiomas are benign, dural-based tumors that originate from the tuberculum sellae, planum sphenoidale or olfactory groove which includes the lamina cribrosa and frontoethmoidal suture. Olfactory groove meningiomas account for $8 \%-13 \%$ of all intracranial meningiomas ${ }^{[1-3]}$, while tuberculum sellae and planum sphenoidale meningiomas constitute around $10 \%-15 \%$ of meningiomas and often present with visual disturbance due to compression of the optic nerves and chiasm ${ }^{[4,5]}$ [Figure 1].

From a pathoanatomical point of view, tuberculum sellae meningiomas are in close anatomical proximity to the optic nerves, optic chiasm, internal carotid artery, and anterior cerebral artery, as well as the hypothalamus, infundibulum and pituitary gland [Figure 2]. In comparison to planum sphenoidale meningiomas, true tuberculum sellae meningiomas are centered on the tuberculum sellae and grow posterosuperiorly displacing the optic nerves superolaterally ${ }^{[6]}$ [Figure 3]. Furthermore, tumor extension into one or both optic canals as well as vascular encasement can take place in many cases and adds to the technical difficulty of resecting these tumors [Figure 4]. On the other hand, olfactory groove meningiomas are in close apposition to the olfactory nerves and tend to infiltrate the cribriform plate, invade the ethmoid and sphenoid sinuses, and engulf the anterior clinoid process as well as the vasculature in their vicinity $^{[1,3,7,8]}$.

Surgical excision is the main treatment modality for these tumors and should ideally aim at complete removal of the tumor as well as the dural tail and invaded bone ${ }^{[9]}$, obviously not an easily achievable or even impossible task when it comes to meningiomas of the skull base, owing to the nature of the anatomical environment surrounding these tumors. Subtotal resection followed by radiation therapy may therefore be an acceptable option in some cases ${ }^{[10]}$. Especially for tuberculum sellae and planum sphenoidale meningiomas, surgical resection results in decompression of the optic nerves and chiasm and therefore prevents further visual deterioration and may reverse neural damage in some cases ${ }^{[10]}$.

Currently, minimally invasive approaches for surgical excision of anterior skull base meningiomas include the endoscopic endonasal approach ${ }^{[11-14]}$ and the endoscope-assisted or endoscope-controlled supraorbital keyhole eyebrow approach ${ }^{[7,15-19]}$. In this article, the endoscope-assisted or endoscope-controlled supraorbital keyhole eyebrow approaches for anterior cranial base meningiomas will be briefly elaborated upon.

\section{SHIFT TOWARDS MINIMALLY INVASIVE APPROACHES FOR ANTERIOR SKULL BASE MENINGIOMAS}

Over several decades, a multitude of traditional transcranial approaches have been developed and effectively used for resection of anterior skull base meningiomas. These approaches include the pterional, bifrontal, extended bifrontal, transbasal, orbitozygomatic, and interhemispheric approaches ${ }^{[2,20-26]}$. Notwithstanding, morbidities related to brain retraction, superior sagittal sinus transection, frontal sinus transgression, optic nerve or chiasm manipulation and wound healing problems ${ }^{[27,28]}$ led to a quest for less invasive alternatives.

Paving the way for the evolution of minimally invasive neurosurgery, advances in the fields of surgical technology, microsurgery, neuroradiology and neuroendoscopy have orchestrated the development of an array of innovative and less traumatizing solutions geared at treating a large spectrum of brain and skull base disorders. Along with this rising tide, novel surgical approaches were developed to treat various pathologies of the anterior skull base including meningiomas originating therein. Probably having more impact than others, advances in endoscopic technology have significantly contributed to the development and refinement of these approaches as they are practiced nowadays. Undeniably, minimally invasive 
A

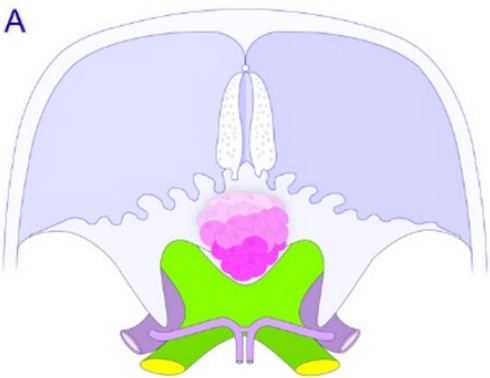

D Tuberculum Sellae Meningioma

Waleed A. Azab 2020
B

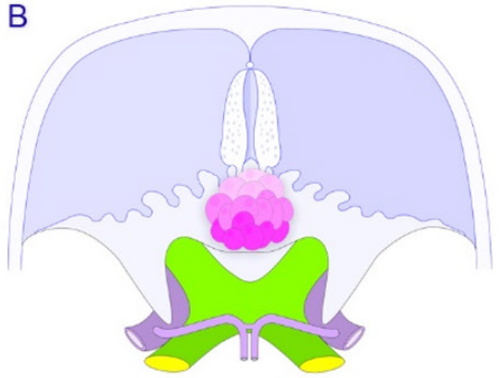

E Planum Sphenoidale Meningioma

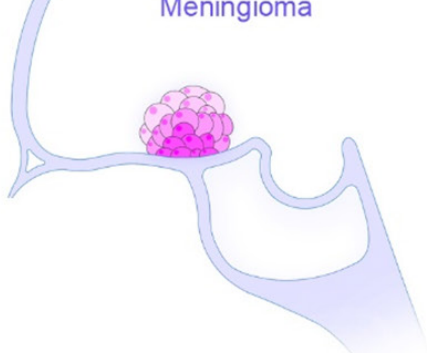

C

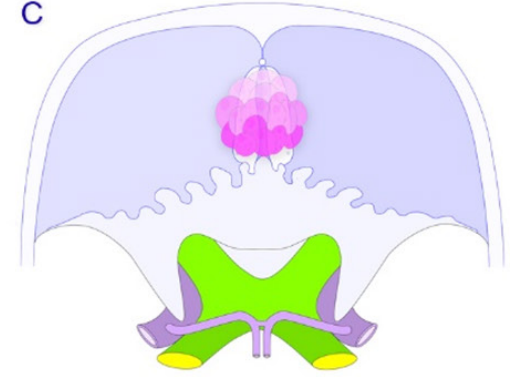

F Olfactory Groove Meningioma

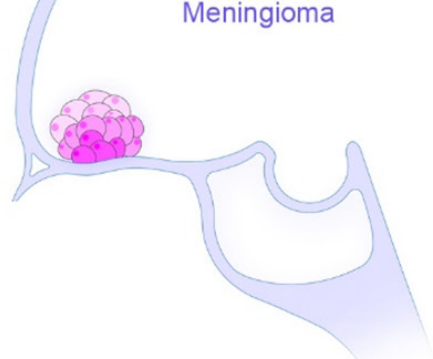

Figure 1. Nomenclature of anterior skull base meningiomas according to anatomical origin in axial (A-C) and sagittal (D-F) views

A
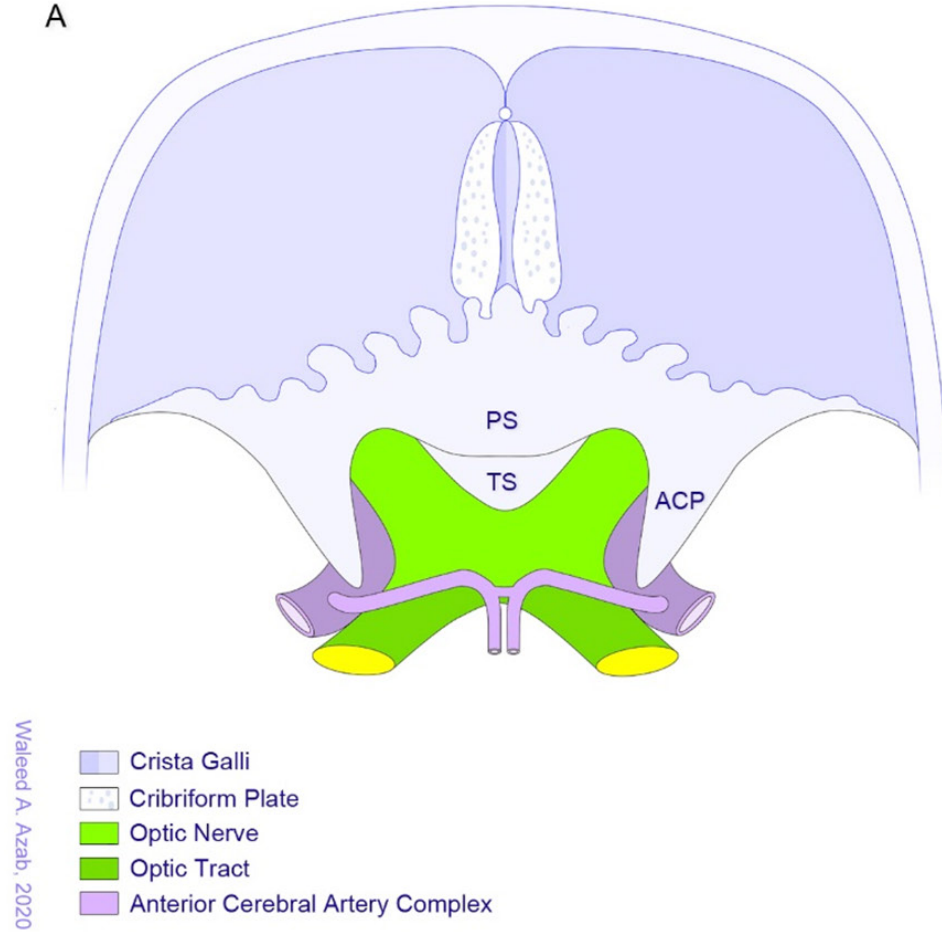

B


Figure 2. Anatomical environment and structures often related to anterior skull base meningioma. A: axial overview; B: sagittal view of the sellar region and structures in its vicinity that may be involved especially in tuberculum sellae and planum sphenoidale meningiomas; $C$ : view of the optic apparatus and the neighboring vasculature. A1: first segment of anterior cerebral artery; ACP: anterior clinoid process; DS: dorsum sellae; ICA: internal carotid artery; MCA: middle cerebral artery; OC: optic chiasm; ON: optic nerve; PG: pituitary gland; PS: planum sphenoidale; PST: pituitary stalk; TS: tuberculum sellae; III: third ventricle 
A

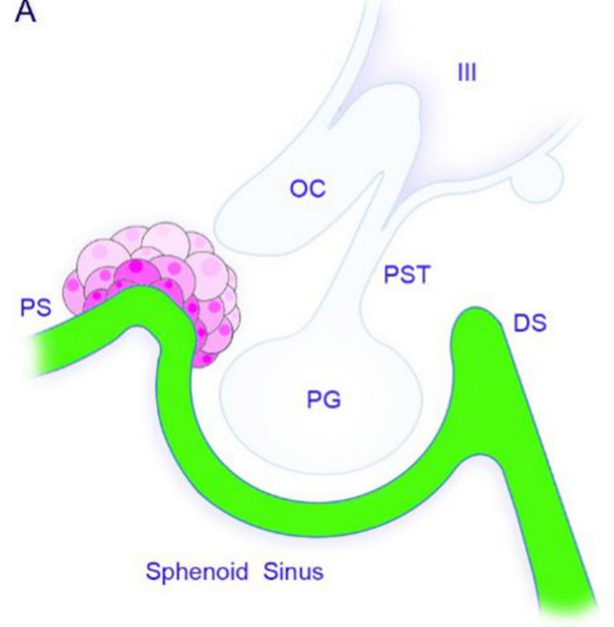

B

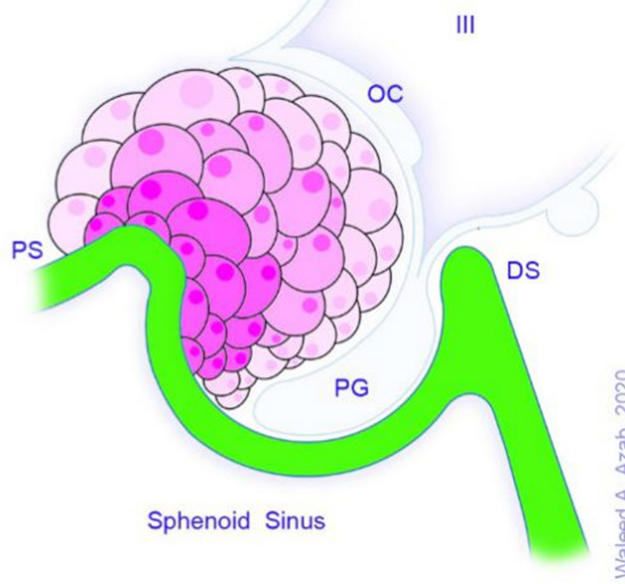

Figure 3. Tuberculum sellae meningiomas can be small (A) or large (B) and are centered on the tuberculum sellae. They grow posterosuperiorly displacing the optic nerves superolaterally. Note the intrasellar extension and compression of the neighboring structures. DS: dorsum sellae; OC: optic chiasm; PG: pituitary gland; PS: planum sphenoidale; PST: pituitary stalk; TS: tuberculum sellae; III: third ventricle

A



B

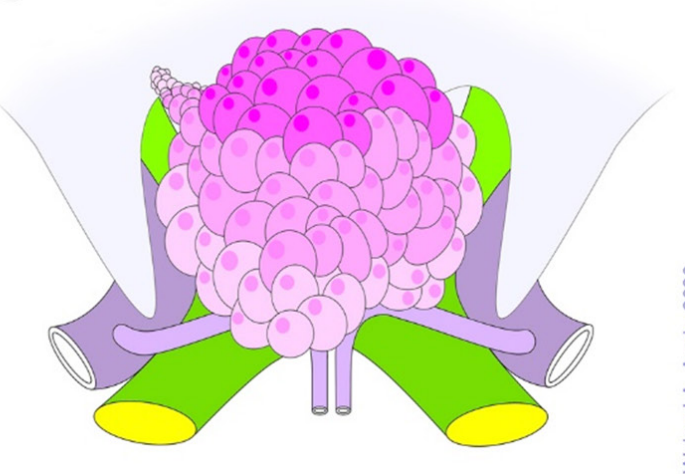

Figure 4. Tuberculum sellae meningiomas frequently extend into the optic canal (A) and may also encase blood vessels in the vicinity (B)

approaches have been shown to be associated with less operative risks, comparable or even better outcomes, more satisfying cosmetic results and faster recovery times in comparison to the classic transcranial approaches ${ }^{[19,27,29]}$.

\section{ENDOSCOPE-ASSISTED AND ENDOSCOPE-CONTROLLED SUPRAORBITAL KEYHOLE APPROACHES}

In 1908, Fedor Krause was the first to describe a supraorbital subfrontal exposure to excise an anterior skull base meningioma ${ }^{[30]}$. Later on, Charles Frazier in 1913 used a supraorbital craniotomy with removal of the orbital rim and roof for surgical resection of a "pituitary cyst" that he described as "seen projecting upward between optic tracts". In Frazier's description, the procedure offered "a splendid exposure of the region of the sella turcica" ${ }^{[31]}$. Donald Wilson was the first to use the term "Keyhole Surgery" in his description of a variety of approaches for supratentorial pathologies. He used small linear incisions and a 2- inch D'Errico trephine to create limited craniotomies that were however sufficiently large to operate through. In his technical note "Limited Exposure in Cerebral Surgery", published in 1971, he pointed out that such operating methodology avoided unnecessary exposure of brain tissue and thus its potential 
damage, and was also associated with better cosmetic results ${ }^{[32]}$. Many decades after these pioneering works, Axel Perneczky popularized the supraorbital keyhole approach through an eyebrow incision and solidly demonstrated the importance of endoscopic assistance in this approach through many published large series of vascular and tumor cases ${ }^{[18,19,29,33]}$.

Compared to classic transcranial approaches, the supraorbital keyhole approach minimizes brain retraction, tissue dissection and length of the skin incision. Temporalis muscle dissection is also very limited so that temporalis muscle atrophy and the consequent mandibular pain and chewing problems are almost nonexistent. Needless to say, the approach yields much better cosmetic results than classic approaches ${ }^{[18,33,34]}$. Much more than what is expected from a mini-craniotomy, the supraorbital eyebrow exposure offers a larger field of view with increasing the distance from the craniotomy as is the case with any keyhole approach ${ }^{[29,34,35]}$. Especially with endoscopic assistance or control, the approach truly provides an excellent view of anterior skull base meningiomas. Additionally, optic nerve decompression is possible under endoscopic view when angled scopes are used ${ }^{[36]}$. Recently, the pure endoscopic (endoscopecontrolled) supraorbital keyhole approach has been used in place of the endoscope-assisted method with promising results ${ }^{[36,37]}$.

\section{ROLE OF THE RIGID ENDOSCOPE IN THE SUPRAORBITAL KEYHOLE EYEBROW APPROACH}

The idea of endoscopic assistance in cranial surgery emerged out of the need to operate via a small opening and yet obtain an appropriate visualization and control of the structures within the field, that is, to perform a minimally invasive yet maximally effective surgery. A closer look the early beginnings of adopting this surgical philosophy sheds the light on how rigid endoscopes were capable of fulfilling this goal by surmounting the hurdle of suboptimal visualization when a small exposure is used.

In 1974, Werner Prott - an otosurgeon from the University of Würzburg- used a rigid endoscope to explore and operate within the cerebellopontine angle. At that time, he preferred a transpyramidal retrolabyrinthine approach via Trautmann's triangle. A bone flap of $1 \mathrm{~cm}$ diameter was made after performing a mastoidectomy and the endoscope was inserted through this narrow space confined between the sigmoid sinus, the superior petrosal sinus, the posterior semicircular canal and the endolymphatic sac without damaging any functional structure of the inner ear or of the cerebellum ${ }^{[38]}$. The same approach was used by Falk Oppel in 1981 for sectioning the sensory root of the trigeminal nerve, glossopharyngeal nerve, and cranial part of the vagus to treat an intractable facial pain in one patient with recurrent deeply seated carcinoma of the upper jaw. The patient's general condition did not permit surgical exploration of the posterior fossa and a "minor" procedure was therefore necessary ${ }^{[39]}$.

Indeed, one of the greatest advantages of a rigid endoscope is that it brings light inside the surgical field, a feature that results in a very highly illuminated area of interest. Moreover, the close proximity of the light source to the structures being viewed eliminates shadows within the field, adding to the extreme clarity of the viewed images. Such superiority of the endoscopic view is also brought about by the high color fidelity and image definition capabilities of today's state-of-the-art rigid endoscopes. Notably, one of the very important optical properties of the rigid endoscope is the greater depth of focus, which simply means that the viewed objects remain in focus within a greater range of distances from the viewing lens. This means lesser need to adjust the focus of the endoscope during the procedure, a feature that results in a seamless operative workflow. The use of angled scopes also enables "looking around the corners", and thereby adds further to the efficacy and safety of the procedure as it brings concealed tumor remnants into view and obviates the need for retraction of neurovascular structures.

On the contrary, the microscope in keyhole surgery requires frequent changing of the viewing angle to allow illumination and visualization of the area of interest deep in the surgical field ${ }^{[40]}$, an inevitable 

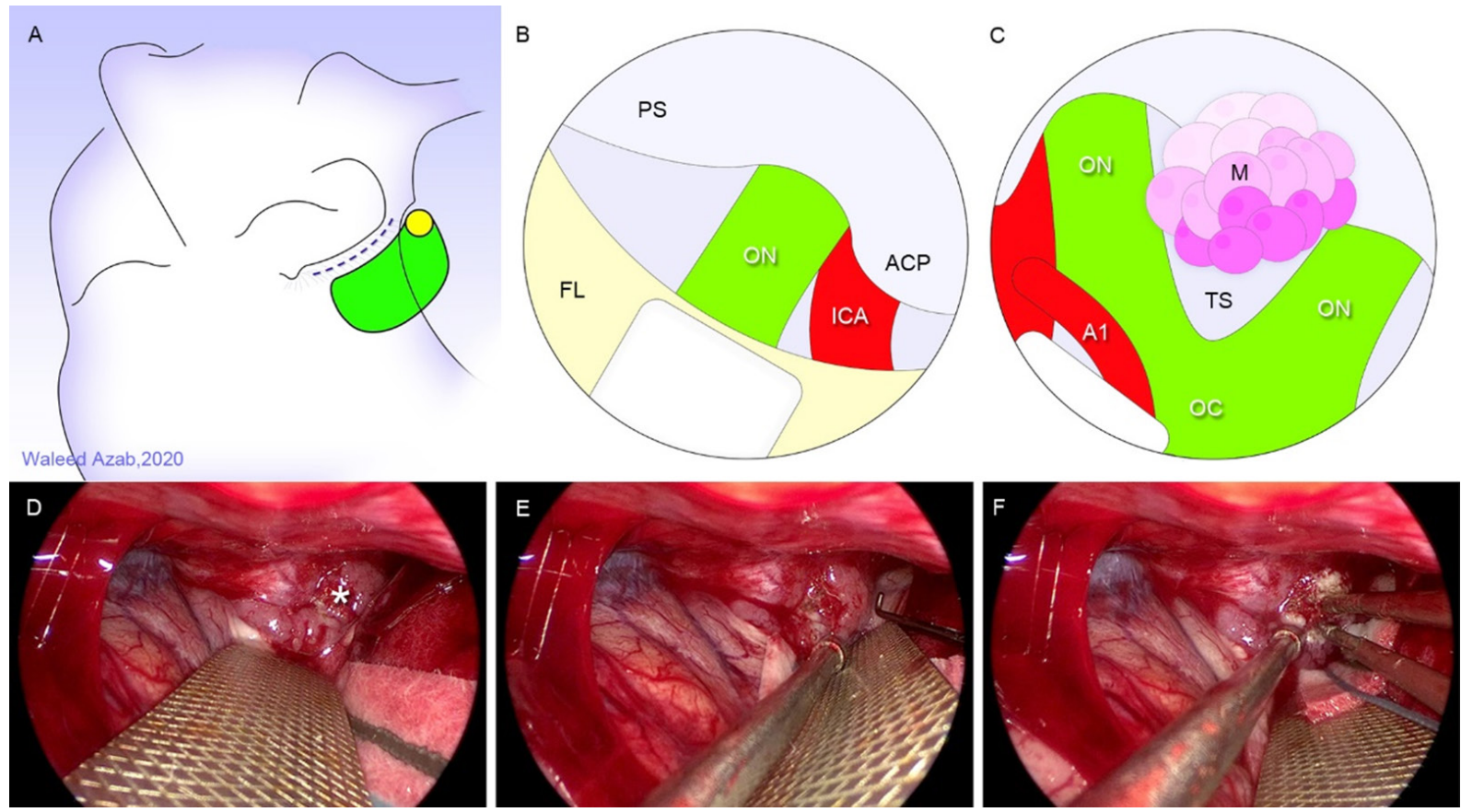

Figure 5. Endoscope-controlled supraorbital keyhole eyebrow approach. A: head position, skin incision, burr hole placement and craniotomy design; B: initial endoscopic view gained through right-sided approach; C: further brain relaxation and panoramic exposure of a tuberculum sellae meningioma; D-F: intraoperative endoscopic views of tuberculum sellae meningioma (asterisk) being exposed with plane development and bipolar coagulation, left-sided approach. A1: first segment of anterior cerebral artery; ACP: anterior clinoid process; ICA: internal carotid artery; FL: frontal lobe; OC: optic chiasm; ON: optic nerve; PS: planum sphenoidale; TS: tuberculum sellae (Illustrations $\mathrm{A}$ through $\mathrm{C}$ by Waleed Azab)

consequence of the light source and the viewing lens being located outside the craniotomy. The loss of light energy at the edges of the small craniotomy and the dropped shadows on the structures within the field further contribute to the lesser quality of the microscopic view obtained during supraorbital keyhole surgery.

Notwithstanding, some disadvantages of endoscope-assisted surgery exist and include the lack of threedimensionality, need for familiarity with endoscopic devices, need to develop eye-hand coordination, and imitation of the operating range of instruments ${ }^{[34]}$. Such disadvantages, however, are largely outweighed by the higher visual quality, surgical radicality and lesser complication profile offered by this type of surgery. In our opinion, rigid endoscopes are indispensable components of the array of surgical tools required to perform a keyhole supraorbital approach. We truly believe endoscopes will completely replace surgical microscopes for this type of surgery in the future.

\section{SURGICAL TECHNIQUE OF THE SUPRAORBITAL KEYHOLE EYEBROW APPROACH [FIGURE 5]}

The surgical technique of the supraorbital keyhole eyebrow approach has been extensively described in the literature ${ }^{[19,29,35,41-46]}$. A brief description of the technique will be given below.

\section{Preoperative planning}

Careful case selection is paramount when operating via the supraorbital eyebrow approach. The patient's individual anatomy should be thoroughly evaluated. One important consideration is the lateral extent of the frontal air sinus which dictates the medial border of the supraorbital craniotomy and determines whether an appropriate surgical trajectory would be possible. Meningiomas with high superior extent need more retroflexion of the head to obtain a proper working trajectory. In general, the closer the tumor to the 
posterior wall of the frontal bone, the more contralateral head rotation is required. Neuronavigation is very important for planning the procedure and should be used in all cases.

Under general anesthesia with the patient in the supine position, the head is secured in a MAYFIELD skull clamp $p^{\circ}$ and rotated $25^{\circ}-30^{\circ}$ to the left for a right-sided approach. The head is then extended $10^{\circ}-15^{\circ}$ to allow a gravitational fall of the frontal lobe away from the skull base. This helps decreasing the brain retraction required to develop the operative corridor. Slight contralateral lateral flexion is then undertaken to help provide easier instrument maneuverability during the procedure.

\section{Skin incision}

The skin incision lies within the eyebrow and starts just lateral to the supraorbital notch - to avoid injury to the supraorbital nerve and consequent postoperative forehead numbness- and ends at the lateral end of the eyebrow over the zygomatic process. In some cases, the incision may be extended laterally a further 5-10 mm in a skin crease without significant cosmetic sequelae.

At the superior temporal line, the temporalis fascia is incised using the monopolar coagulation for about $2 \mathrm{~cm}$ and the frontalis fascia is then cut from the temporal line in a semicircular fashion over the frontal bone with its base at the orbital rim. The temporalis muscle is subsequently dissected off the bone and retracted posteriorly for $1-2 \mathrm{~cm}$.

\section{Craniotomy}

A single burr hole is made using a sharp pit attached to the high-speed drill in the temporal fossa lateral to the superior temporal line. The burr hole position is chosen at a point that is slightly higher than the classic MacCarty's burr hole. A frontal direction of drilling prevents entering the orbit. A craniotome is then used to perform a 2-3.5 $\mathrm{cm} \times 2-2.5 \mathrm{~cm}$ bone flap. Care should be taken to avoid opening the frontal air sinus at the medial border of the craniotomy. Small bony extensions of the frontal skull base should be drilled off extradurally and the inner edge of the craniotomy is to be beveled to increase the space available for instrument maneuverability and to gain unobstructed view in the depth of the field.

\section{Dural opening and intradural steps}

The dural flap is fashioned with its base at the orbital roof. Under microscopic or endoscopic control, the subfrontal corridor is developed. The ipsilateral optic nerve and supraclinoid carotid artery are identified, and the arachnoid membranes of the optico-carotid and carotid-occulomotor cisterns are opened to allow CSF egress. CSF release is essential to achieve adequate brain relaxation that opens the surgical corridor. The rigid 4-mm endoscope is held by an assistant or fixed by a holder during an endoscope-controlled procedure. An irrigation sheath is very helpful to clear the smudged lens. Surgery then proceeds using the standard microsurgical techniques. It should be noted that tuberculum sellae meningiomas grow in a subchiasmatic location displacing the optic chiasm backwards and the optic nerves laterally and superiorly creating a prechiasmatic working space and facilitating the resection of these tumors via a supraorbital eyebrow approach ${ }^{[4]]}$. In far anterior olfactory groove meningiomas, visualization of the attachment point of the tumor in the midline depression of the olfactory groove may not be possible with the operating microscope. This can be overcome with an angled endoscope and angled instruments ${ }^{[35]}$. Wound closure is then undertaken in the usual manner.

\section{Approach selection for anterior skull base meningiomas: endoscope-assisted supraorbital keyhole versus endoscopic endonasal surgery}

Advances in endoscopic technology ${ }^{[48]}$ and the subsequent development of the expanded endoscopic endonasal approach ${ }^{[6,49]}$ created significant controversy regarding whether an endonasal or a keyhole supraorbital approach provides the best results ${ }^{[6,10,50]}$. On the one hand, the advantages of endoscopic 

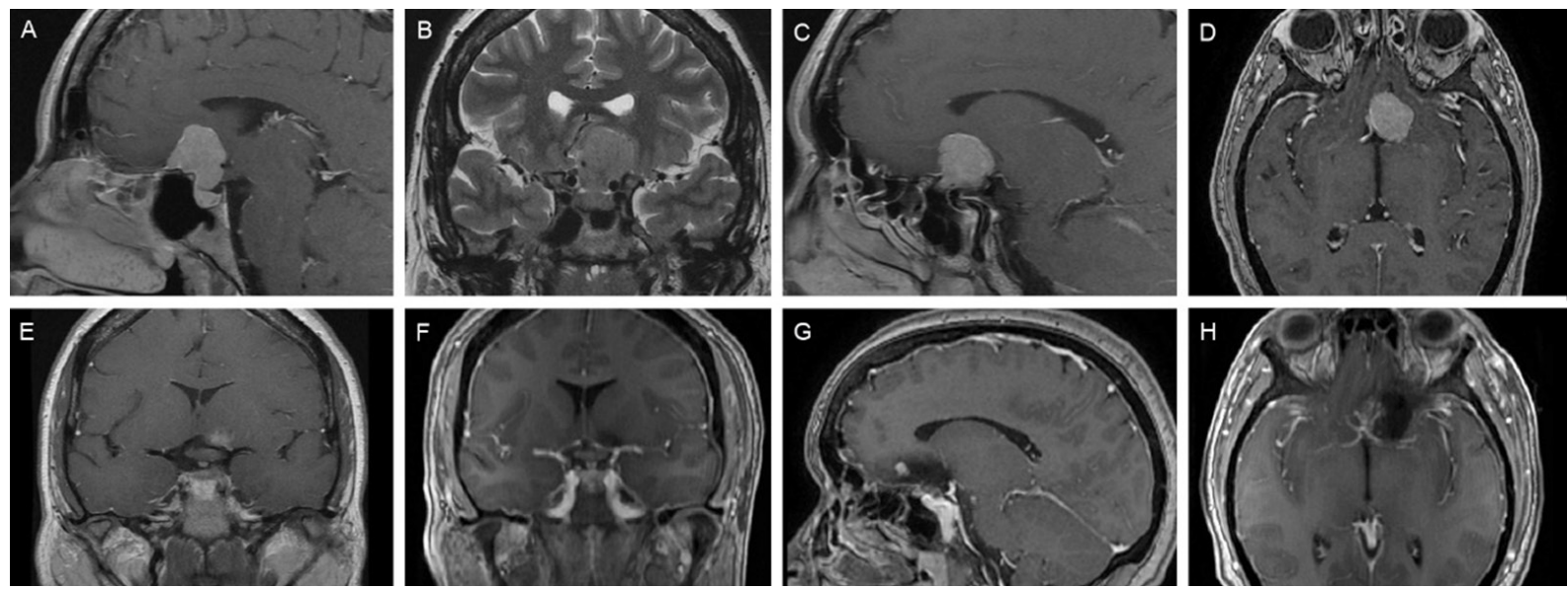

Figure 6. Pre- $(A-E)$ and postoperative $(F-H)$ magnetic resonance images in a case of tuberculum sellae meningioma excised via an endoscope-controlled keyhole supraorbital approach. Extension beyond the internal carotid on the left and anterior cerebral artery encasement on the right led to selection of endoscope-assisted keyhole transcranial approach instead of an extended endoscopic endonasal transsphenoidal approach

endonasal over supraorbital keyhole approach include early devascularization of the tumor, less manipulation of the optic nerves, chiasm and brain, better visualization of the medial optic canal allowing removal of intracanalicular tumor extensions, removal of all involved bone at the skull base and access to potentially invaded intranasal structures such as the ethmoid cells ${ }^{[10,34,51]}$. The advantages of the supraorbital keyhole over the endoscopic endonasal approach, on the other hand, include avoidance of an infected field, avoidance of trauma to the nasal passages and olfactory mucosa, and a wider view of the lateral extent of the tumor, making it more suitable for tumors with extension lateral to the carotid artery or optic nerve and for tumors with vascular encasement ${ }^{[10,34]}$. Although CSF leaks are less frequent following the supraorbital keyhole approach, the incidence of CSF leakage that initially complicated expanded endonasal skull base approaches has been reduced dramatically with the advent of the nasoseptal flap ${ }^{[6,52]}$.

Across the literature, a limited number of studies exist that directly compare the endoscopic endonasal versus supraorbital keyhole approach for resection of anterior cranial base meningiomas. In these studies, scores and algorithms have been suggested to help select the suitable approach ${ }^{[3,6,27,42,50,53]}$ [Figure 6]. As a matter of fact, one of the important factors that lessen the credibility and practical applicability of the results of such studies, however, is that the indications for each approach may differ, and it is impossible to compare two approaches for removal of the very same tumor ${ }^{[10]}$.

Although a detailed account of the published results is beyond the scope of this review, it is important to note that for olfactory groove meningiomas, the endoscope-assisted supraorbital eyebrow approach leads to a higher extent of resection and lower rate of complications than the purely endoscopic endonasal approach $^{[7]}$. while for tuberculum sellae and planum sphenoidale meningiomas, the two approaches yield more or less similar rates of gross total resection, near total resection and visual recovery ${ }^{[34]}$. It should be borne in mind that not all anterior skull base meningiomas are amenable to minimally invasive approaches $^{[27]}$.

In a recently published meta-analysis, Khan et al. ${ }^{[54]}$ compared the endoscope-assisted supraorbital keyhole approach with the microscopic transcranial and expanded endoscopic endonasal approaches for surgical resection of olfactory groove and tuberculum sellae meningiomas. In the authors conclusions, case selection was paramount in establishing the role of endoscope-assisted keyhole surgery in these tumors. 
In our opinion, the ideal approach should be tailored to the individual patient according to the tumor size, lateral extension, optic canal involvement, extent of vascular encasement and surgeon's experience. We currently make the selection of the approach on a case-by-case basis without following a specific algorithm.

\section{CONCLUSION}

Endoscope-assisted or endoscope-controlled supraorbital keyhole transcranial approach is a highly effective approach for excision of anterior skull base meningiomas. It offers a minimally invasive option that overcomes the pathoanatomical constraints that preclude using an extended endoscopic endonasal approach in some cases.

\section{DECLARATIONS}

\section{Authors' contributions}

All authors made substantial contributions to the conception and design of the article, performed data acquisition, and provided administrative, technical and material support as well: Azab WA, Elmaghraby MA, Zaidan SN, Mostafa KH

Made the illustrations for the article: Azab WA

\section{Availability of data and materials}

Not applicable.

\section{Financial support and sponsorship}

None.

\section{Conflicts of interest}

All authors declared that there are no conflicts of interest.

\section{Ethical approval and consent to participate}

Not applicable.

\section{Consent for publication}

Not applicable.

\section{Copyright}

(c) The Author(s) 2020.

\section{REFERENCES}

1. Liu JK, Silva NA, Sevak IA, Eloy JA. Transbasal versus endoscopic endonasal versus combined approaches for olfactory groove meningiomas: importance of approach selection. Neurosurg Focus 2018;44:E8.

2. Pallini R, Fernandez E, Lauretti L, et al. Olfactory groove meningioma: report of 99 cases surgically treated at the Catholic University School of Medicine, Rome. World Neurosurg 2015;83:219-31.e1-3.

3. Komotar RJ, Starke RM, Raper DM, Anand VK, Schwartz TH. Endoscopic endonasal versus open transcranial resection of anterior midline skull base meningiomas. World Neurosurg 2012;77:713-24.

4. Kane AJ, Sughrue ME, Rutkowski MJ, et al. Anatomic location is a risk factor for atypical and malignant meningiomas. Cancer 2011;117:1272-8.

5. Ruggeri AG, Cappelletti M, Fazzolari B, Marotta N, Delfini R. Frontobasal midline meningiomas: is it right to shed doubt on the transcranial approaches? Updates and review of the literature. World Neurosurg 2016;88:374-82.

6. Magill ST, Morshed RA, Lucas CG, et al. Tuberculum sellae meningiomas: grading scale to assess surgical outcomes using the transcranial versus transsphenoidal approach. Neurosurg Focus 2018;44:E9.

7. Banu MA, Mehta A, Ottenhausen M, et al. Endoscope-assisted endonasal versus supraorbital keyhole resection of olfactory groove meningiomas: comparison and combination of 2 minimally invasive approaches. J Neurosurg 2016;124:605-20.

8. Guinto G. Olfactory groove meningiomaas. World Neurosurg 2015;83:1046-7. 
9. Simpson D. The recurrence of intracranial meningiomas after surgical treatment. J Neurol Neurosurg Psychiatry 1957;20:22-39.

10. Bander ED, Singh H, Ogilvie CB, et al. Endoscopic endonasal versus transcranial approach to tuberculum sellae and planum sphenoidale meningiomas in a similar cohort of patients. J Neurosurg 2018;128:40-8.

11. Hayhurst C, Sughrue ME, Gore PA, Bonney PA, Burks JD, Teo C. Results with expanded endonasal resection of skull base meningiomas technical nuances and approach selection based on an early experience. Turk Neurosurg 2016;26:662-70.

12. Koutourousiou M, Fernandez-Miranda JC, Wang EW, Snyderman CH, Gardner PA. Endoscopic endonasal surgery for olfactory groove meningiomas: outcomes and limitations in 50 patients. Neurosurg Focus 2014;37:E8.

13. Cavallo LM, de Divitiis O, Aydin S, et al. Extended endoscopic endonasal transsphenoidal approach to the suprasellar area: anatomic considerations--part 1. Neurosurgery 2007;61:24-34.

14. de Divitiis E, Cavallo LM, Cappabianca P, Esposito F. Extended endoscopic endonasal transsphenoidal approach for the removal of suprasellar tumors: Part 2. Neurosurgery 2007;60:46-59.

15. Gandhoke GS, Pease M, Smith KJ, Sekula RF Jr. Supraorbital versus endoscopic endonasal approaches for olfactory groove meningiomas: a cost-minimization study. World Neurosurg 2017;105:126-36.

16. Telera S, Carapella CM, Caroli F, et al. Supraorbital keyhole approach for removal of midline anterior cranial fossa meningiomas: a series of 20 consecutive cases. Neurosurg Rev 2012;35:67-83.

17. Iacoangeli M, Nocchi N, Nasi D, et al. Minimally invasive supraorbital key-hole approach for the treatment of anterior cranial fossa meningiomas. Neurol Med Chir (Tokyo) 2016;56:180-5.

18. Reisch R, Perneczky A. Ten-year experience with the supraorbital subfrontal approach through an eyebrow skin incision. Neurosurgery 2005;57:242-55.

19. van Lindert E, Perneczky A, Fries G, Pierangeli E. The supraorbital keyhole approach to supratentorial aneurysms: concept and technique. Surg Neurol 1998;49:481-90.

20. Bitter AD, Stavrinou LC, Ntoulias G, et al. The role of the pterional approach in the surgical treatment of olfactory groove meningiomas: a 20-year experience. J Neurol Surg B Skull Base 2013;74:97-102.

21. Ciurea AV, Iencean SM, Rizea RE, Brehar FM. Olfactory groove meningiomas: a retrospective study on 59 surgical cases. Neurosurg Rev 2012;35:195-202.

22. Nakamura M, Struck M, Roser F, Vorkapic P, Samii M. Olfactory groove meningiomas: clinical outcome and recurrence rates after tumor removal through the frontolateral and bifrontal approach. Neurosurgery 2007;60:844-52.

23. Nanda A, Maiti TK, Bir SC, Konar SK, Guthikonda B. Olfactory groove meningiomas: comparison of extent of frontal lobe changes after lateral and bifrontal approaches. World Neurosurg 2016;94:211-21.

24. Safaee MM, McDermott MW, Benet A, Theodosopoulos PV. Tailored extended bifrontal craniotomy for anterior skull base tumors: anatomic description of a modified surgical technique and case series. Oper Neurosurg (Hagerstown) 2018;14:386-94.

25. Ganna A, Dehdashti AR, Karabatsou K, Gentili F. Fronto-basal interhemispheric approach for tuberculum sellae meningiomas; long-term visual outcome. Br J Neurosurg 2009;23:422-30.

26. Goel A, Muzumdar D, Desai KI. Tuberculum sellae meningioma: a report on management on the basis of a surgical experience with 70 patients. Neurosurgery 2002;51:1358-64.

27. Ottenhausen M, Rumalla K, Alalade AF, et al. Decision-making algorithm for minimally invasive approaches to anterior skull base meningiomas. Neurosurg Focus 2018;44:E7.

28. Borghei-Razavi H, Truong HQ, Fernandes-Cabral DT, et al. Minimally invasive approaches for anterior skull base meningiomas: supraorbital eyebrow, endoscopic endonasal, or a combination of both? anatomic study, limitations, and surgical application. World Neurosurg 2018;112:e666-74.

29. Perneczky A, Müller-Forell W, van Lindert E, Fries G. Keyhole concept in neurosurgery: with endoscope-assisted microsurgery and case studies. 1st ed. Stuttgart: Thieme Medical Publishers; 1999.

30. Krause F, Haubold H. Surgery of the brain and spinal cord: based on personal experiences. Thorek M [Trans]. New York: Rebman Company; 1909-12.

31. Frazier CH. I. An approach to the hypophysis through the anterior cranial fossa. Ann Surg 1913;57:145-50.

32. Wilson DH. Limited exposure in cerebral surgery. Technical note. J Neurosurg 1971;34:102-6.

33. Fries G, Perneczky A. Endoscope-assisted brain surgery: part 2--analysis of 380 procedures. Neurosurgery 1998;42:226-32.

34. Linsler S, Fischer G, Skliarenko V, Stadie A, Oertel J. Endoscopic assisted supraorbital keyhole approach or endoscopic endonasal approach in cases of tuberculum sellae meningioma: which surgical route should be favored?. World Neurosurg 2017;104:601-11.

35. Wilson DA, Duong H, Teo C, Kelly DF. The supraorbital endoscopic approach for tumors. World Neurosurg 2014;82:S72-80.

36. Arnaout MM, Luzzi S, Galzio R, Aziz K. Supraorbital keyhole approach: pure endoscopic and endoscope-assisted perspective. Clin Neurol Neurosurg 2020;189:105623.

37. Berhouma M, Jacquesson T, Jouanneau E. The fully endoscopic supraorbital trans-eyebrow keyhole approach to the anterior and middle skull base. Acta Neurochir (Wien) 2011;153:1949-54.

38. Prott W. Cisternoscopy? Endoscopy of the cerebellopontine angle. Acta neurochir 1974;31:105-13.

39. Oppel F, Mulch G, Brock M. Endoscopic section of the sensory trigeminal root, the glossopharyngeal nerve, and the cranial part of the vagus for intractable facial pain caused by upper jaw carcinoma. Surg Neurol 1981;16:92-5.

40. Ormond DR, Hadjipanayis CG. The supraorbital keyhole craniotomy through an eyebrow incision: its origins and evolution. Minim Invasive Surg 2013;2013:296469.

41. Czirják S, Nyáry I, Futó J, Szeifert GT. Bilateral supraorbital keyhole approach for multiple aneurysms via superciliary skin incisions. 
Surg Neurol 2002;57:314-24.

42. Fatemi N, Dusick JR, de Paiva Neto MA, Malkasian D, Kelly DF. Endonasal versus supraorbital keyhole removal of craniopharyngiomas and tuberculum sellae meningiomas. Neurosurgery 2009;64:269-86.

43. Hayhurst C, Teo C. Tuberculum sella meningioma. Otolaryngol Clin North Am 2011;44:953-63, viii-ix.

44. Jallo GI, Bognár L. Eyebrow surgery: the supraciliary craniotomy: technical note. Neurosurgery 2006;59:ONSE157-8.

45. McLaughlin N, Ditzel Filho LF, Shahlaie K, Solari D, Kassam AB, Kelly DF. The supraorbital approach for recurrent or residual suprasellar tumors. Minim Invasive Neurosurg 2011;54:155-61.

46. Reisch R, Perneczky A, Filippi R. Surgical technique of the supraorbital key-hole craniotomy. Surg Neurol 2003;59:223-7.

47. Cai M, Hou B, Luo L, Zhang B, Guo Y. Trans-eyebrow supraorbital keyhole approach to tuberculum sellae meningiomas: a series of 30 cases with long-term visual outcomes and recurrence rates. J Neurooncol 2019;142:545-55.

48. Doglietto F, Prevedello DM, Jane JA Jr, Han J, Laws ER Jr. Brief history of endoscopic transsphenoidal surgery--from philipp bozzini to the first world congress of endoscopic skull base surgery. Neurosurg Focus 2005;19:E3.

49. Kassam A, Snyderman CH, Mintz A, Gardner P, Carrau RL. Expanded endonasal approach: the rostrocaudal axis. Part I. Crista galli to the sella turcica. Neurosurg Focus 2005;19:E3.

50. de Divitiis E, Esposito F, Cappabianca P, Cavallo LM, de Divitiis O. Tuberculum sellae meningiomas: high route or low route? A series of 51 consecutive cases. Neurosurgery 2008;62:556-63.

51. Attia M, Kandasamy J, Jakimovski D, et al. The importance and timing of optic canal exploration and decompression during endoscopic endonasal resection of tuberculum sella and planum sphenoidale meningiomas. Neurosurgery 2012;71:58-67.

52. Hadad G, Bassagasteguy L, Carrau RL, et al. A novel reconstructive technique after endoscopic expanded endonasal approaches: vascular pedicle nasoseptal flap. Laryngoscope 2006;116:1882-6.

53. Kitano M, Taneda M, Nakao Y. Postoperative improvement in visual function in patients with tuberculum sellae meningiomas: results of the extended transsphenoidal and transcranial approaches. J Neurosurg 2007;107:337-46.

54. Khan DZ, Muskens IS, Mekary RA, et al. The endoscope-assisted supraorbital "keyhole" approach for anterior skull base meningiomas: an updated meta-analysis. Acta Neurochir (Wien) 2020;1-16. 